
\title{
28 Research Square \\ Efficacy of Endoscopic Gallbladder Drainage in Patients with Acute Cholecystitis
}

\author{
Hirotaka Sasada \\ Kensei Hospital

\section{Takuma Matsumoto} \\ Kensei hospital

\section{Tsuyoshi Sakai} \\ Kensei hospital

\section{Shuichi Sato} \\ Kensei hospital

\section{Takashi Hara} \\ Kensei Hospital
}

Anri Kaneta ( $\nabla$ tabata0818@yahoo.co.jp )

Kensei Hospital https://orcid.org/0000-0001-6131-0609

\section{Research Article}

Keywords: Acute cholecystitis, gallbladder drainage, endoscopic trans-papillary gallbladder drainage, percutaneous transhepatic gallbladder drainage, laparoscopic cholecystectomy, subtotal cholecystectomy

Posted Date: March 1st, 2022

DOI: https://doi.org/10.21203/rs.3.rs-1199046/v1

License: (c) (i) This work is licensed under a Creative Commons Attribution 4.0 International License. Read Full License 


\section{Abstract}

Background. Early cholecystectomy is recommended for patients with acute cholecystitis. However, emergency surgery may not be indicated due to complications and disease severity. Patients requiring drainage are usually treated with percutaneous transhepatic gallbladder drainage (PTGBD), whereas patients with biliary duct stones undergo endoscopic stones removal followed by endoscopic gallbladder drainage (EGBD). Herein, we investigated the efficacy of EGBD in patients with acute cholecystitis.

Methods. Overall, 101 patients receiving laparoscopic cholecystectomy between September 2019 and September 2020 in our department were retrospectively analyzed.

Results. The patients $(n=101)$ were divided into three groups: control group that did not undergo drainage $(n=67)$, a group that underwent EGBD $(n=7)$, and a group that underwent PTGBD $(n=27)$. Average surgery time was 124.0, 191.9, and 150.7 minutes, respectively. Control group had a significantly shorter surgery time, whereas it did not significantly differ between EGBD and PTGBD groups. The average amount of bleeding was $11.8 \mathrm{~g}, 7.1 \mathrm{~g}$, and $30.6 \mathrm{~g}$, respectively, and control group had significantly less bleeding than PTGBD group. We further divided patients into the following subgroups: patients requiring a 5-mm clip to ligate the cystic duct, patients requiring a $10-\mathrm{mm}$ clip due to the thickness of the cystic duct, patients requiring an automatic suturing device, and patients undergoing subtotal cholecystectomy due to impossible cystic duct ligation. There was no significant difference between EGBD and PTGBD regarding the clip used or the need for an automatic suturing device and subtotal cholecystectomy.

Conclusion. There was no significant difference between EGBD and PTGBD groups regarding surgery time or bleeding amount when surgery was performed after gallbladder drainage for acute cholecystitis. Therefore, EGBD was considered a useful preoperative drainage method requiring no drainage bag.

\section{Background}

Early cholecystectomy is a standard therapy for acute cholecystitis (AC) [1, 2]. However, early surgical intervention may result in increased morbidity and mortality in the elderly, patients with multiple comorbidities, or those with advanced cholecystitis [3]. According to Tokyo guidelines 2018, early gallbladder drainage is should be considered for patients with severe local inflammation and/or severe (grade III) AC [4].

Percutaneous transhepatic gallbladder drainage (PTGBD) is a widely performed and established method for gallbladder drainage. However, PTGBD is generally prohibited in patients with a breeding tendency, massive ascites, and anatomically inaccessible gallbladders. In addition, PTGBD is associated with adverse events, including bleeding, and catheter dislodgement. There are several reports on the usefulness and safety of endoscopic gallbladder drainage (EGBD), including endoscopic nasogallbladder drainage (ENGBD) and endoscopic gallbladder stenting, and endoscopic ultrasound-guided gallbladder drainage (EUS-GBD) in patients with AC [5-7]. However, there have been few studies comparing the 
feasibility of laparoscopic cholecystectomy (LC) for AC after EGBD and LC after PTGBD $[8,9]$. The objective of this study was to evaluate the feasibility of LC after EGBD compared with PTGBD.

\section{Methods}

\section{Study population}

Overall, 101 patients who underwent LC for AC between September 2019 and September 2020 in our department were retrospectively analyzed. Of these, 33 patients who underwent LC for AC after gallbladder drainage were included in the analysis (Fig. 1). This retrospective study was approved by the Medical Ethics Committee of Kensei Hospital (no. 2021-03) and performed following the ethical guidelines for clinical studies.

\section{Treatment}

In our institution, urgent or semi-urgent LC was performed for AC patients tolerant for surgery. If surgery was unsuitable, AC patients were treated in a gastroenterology department. In addition to antibiotic treatment, gallbladder drainage was performed depending on disease course and severity. In most cases, PTGBD was selected as the drainage method. EGBD was selected for patients suspected of choledocholithiasis, bleeding tendency, and dementia with a risk of drainage tube self-removal.

\section{PTGBD}

PTGBD was guided by ultrasound. After an 18-gauge needle was inserted into the gallbladder, a guidewire was coiled into the gallbladder. And then, a pigtail catheter was placed using a guidewire under fluoroscopy.

\section{EGBD}

The term EGBD generally includes ENGBD and EUS-GBD, but these are not performed in our institution. In the text, EGBD means endoscopic trans-papillary gallbladder drainage. Following endoscopic retrograde cholangiopancreatography (ERCP), a 0.035-inch Radifocus guidewire (Terumo, Tokyo, Japan) was advanced into the cystic duct and subsequently into the gallbladder. A 5-French IYO-stent ${ }^{\mathrm{TM}}(32 \mathrm{~cm}$, Gadelius Medical K.K., Tokyo, Japan) was inserted into the gallbladder along the guidewire (Fig 2).

\section{Surgery after drainage}

Because most studies determined that a short interval between PTGBD and LC can increase the intraoperative difficulty [10-12], LC was basically performed at least 2 months after drainage so that edema and inflammation around the gallbladder subsided. All EGBD tubes were removed before LC.

\section{Patient variables}


The characteristics of EGBD and PTGBD patients before gallbladder drainage were compared. Surgical results in patients with and without gallbladder drainage were compared. In addition, surgical results in EGBD and PTGBD patients were compared. The severity of AC was determined by the Tokyo guideline criteria [4].

\section{Statistical analysis}

Categorical variables were compared using the chi-square test and Fisher's exact test, and continuous variables were compared using Mann-Whitney U-test. A $P<0.05$ was considered significant for all tests. The statistical analysis was performed with js-STAR XR release 1.1.3j.

\section{Results}

Patient status before drainage is summarized in Table 1. There were no significant differences in age, sex, anticoagulant therapy, and severity of AC between the two groups. The time to operation day was significantly shorter in PTGBD group. There was no significant difference, but five PTGBD patients had severe Tokyo grade III AC whereas there were no grade III patients in EGBD group.

Surgical results in patients with and without gallbladder drainage are shown in Table 2. There are significant differences in the variables as follows; surgery time, blood loss, cystic duct closure, and hospital stay. In all of these, non-drainage group had a better result, but only the non-drainage group had postoperative complications.

Intra- and postoperative factors in EGBD and PTGBD groups are summarized in Table 3. The median surgery times were $166 \mathrm{~min}$ (range, 76-299) for EGBD and $143 \mathrm{~min}$ (range, 75-264) for PTGBD $(P=0.4)$. In both groups, there was no conversion to open surgery.

If the critical view of safety could not be established, Fundus first technique was performed. Furthermore, if it was difficult to identify the cystic duct, laparoscopic subtotal cholecystectomy was performed. There was no significant difference between the groups in cystic duct closure, but ligation with a $5-\mathrm{mm}$ clip was difficult in EGBD group, and automatic suturing devices tended to be used more often. There were no postoperative complications in both groups. There was no significant difference in postoperative hospital stay between the two groups.

\section{Discussion}

According to 2018 Tokyo guidelines, the first surgical treatment of choice for mild or moderate AC is LC. Gallbladder drainage is required as the initial treatment in severe AC for whom urgent surgery is contraindicated due to comorbidity and organopathy [4]. Since drainage is often performed in severe cases, inflammation increases the difficulty of cholecystectomy. The optimal timing of cholecystectomy after drainage is still without consensus, but there are some reports that delayed surgery after drainage can be performed more safely than early surgery [10-13]. Then, we required most patients to undergo LC 
at least 2 months after drainage. In drainage group, although surgery time, blood loss, and hospital stay increased, postoperative complications did not increase, demonstrating the adequacy of the treatment strategy (Table 2).

PTGBD is a frequently performed and established method for gallbladder drainage. A previous systematic review showed that the technical success rate of PTGBD was 98\% [14]. However, we speculate that the external tube might decrease the quality of life $(\mathrm{QOL})$ while awaiting surgery due to postprocedural pain and discomfort. Additional associated risks include catheter dislodgment, bile leakage, bleeding, and pneumothorax [15]. On the other hand, EGBD is a complex procedure with a reported success rate of $77-91 \%[9,16-21]$. Failure of EGBD was mostly attributable to the inability to detect the cystic duct and insert the guidewire or the stent due to an obstruction caused by severe inflammation and gallstones within the duct [7]. Therefore, EGBD requires an expert endoscopist. EGBD had a similar technical success rate to PTGBD but seems to be safer because it has lower complication rate than PTGBD, according to a meta-analysis [22]. It has also been reported that EGBD is superior to PTGBD in the patient's QOL and hospitalization period $[9,21,23]$. We did not evaluate QOL after the drainage, but as shown in Table1, it is considered that a significantly longer time to operation was possible because of less discomfort and stent trouble in the EGBD group. In most cases, the ultimate goal of treating $\mathrm{AC}$ is safe cholecystectomy. Although the efficacy of EGBD is gradually being established, there are few reports on its effect on surgery. There are concerns that surgery after EGBD might be more difficult because inflammation around the cystic duct and cannulation of the drainage tube interfere with dissection in Calot's triangle. In this patient series, only in one case in EGBD group, a ligation with a 5-mm clip was possible; thus, the cystic duct may tend to thicken after EGBD. However, there was no significant difference between EGBD and PTGBD in cystic duct closure. Cannulation of the drainage tube may not affect dissection in Calot's triangle so much. And then EGBD did not increase the difficulty of surgery compared with PTGBD. Surgery time and blood loss were equivalent. The postoperative complication and hospital stay were also equivalent (Table 3). Therefore, EGBD was considered useful as a preoperative drainage method.

The limitation of this study was its retrospective analysis, a small number of patients, and investigation in a single institution. In order to further explore the actual feasibility of LC after EGBD, it needs to be investigated by prospective studies.

\section{Conclusion}

EGBD could be a safe and effective alternative treatment to PTGBD for patients with AC who are unsuitable for emergency cholecystectomy. This study showed that LC was performed successfully and safely after either EGBD or PTGBD. The feasibility of LC after EGBD was comparable to LC after PTGBD. However, based on the limits of the current study, large sample, multi-center studies are still needed.

\section{Abbreviations}


AC Acute cholecystitis

EGBD Endoscopic gallbladder drainage

LC Laparoscopic cholecystectomy

PTGBD Percutaneous transhepatic gallbladder drainage

\section{Declarations}

\section{Ethics approval and consent to participate}

This retrospective study was approved by the Medical Ethics Committee of Kensei Hospital (no. 2021-03) and performed following the ethical guidelines for clinical studies. Informed consent was obtained in the form of opt-out on the web-site of our institution.

\section{Consent for publication}

Not applicable.

\section{Availability of data and materials}

The data and materials used and/or analyzed during the current study are available from the corresponding author on reasonable request.

\section{Competing interests}

The authors confirm that they no competeng interests.

\section{Funding}

Not applicable.

\section{Authors' contributions}

HS contributed to research design. AK, TM, and HS collected the data. AK and HS analyzed the data. AK drafted the manuscript. HS, SS, TS, TM, and TH contributed to revising the manuscript. All authors read and approved the final manuscript.

\section{Acknowledgements}

The authors would like to thank Enago (www.enago.jp) for the English language review.

\section{References}


1. Duncan CB, Riall TS. Evidence-based current surgical practice: calculous gallbradder disease. J Gastrointest Surg. 2012;16:2011-25.

2. Yokoe M, Takada T, Hwang TL, Endo I, Akazawa K, Miura F, et al. Descriptive review of acute cholecystitis: Japan-Taiwan collaborative epidemiological study. J Hepatobilialy Pancreat Sci. 2017;24:319-28.

3. Hannan EL, Imperato PJ, Nenner RP, Starr H. Laparoscopic and open cholecystectomy in New York State: mortality, complications, and choice of procedure. Surgery. 1999;125:223-31.

4. Mori Y, Itoi T, Baron TH, Takada T, Strasberg SM, Pitt HA, et al. Tokyo guidelines 2018: management strategies for gallbladder drainage in patients with acute cholecystitis (with videos). J Hepatobiliary Pancreat Sci. 2018;25:87-95.

5. Yang Mj, Yoo BM, Kim JH, Hwang JC, Baek NH, Kim SS, et al. Endoscopic naso-gallbladder drainage versus gallbladder stenting before cholecystectomy in patients with acute cholecystitis and a high suspicion of choledocholithiasis: a prospective randomized preliminary study. Scand J Gastroenterol. 2016;51:472-8.

6. Jang JW, Lee SS, Song TJ, Hyun YS, Park DY, Seo DW, et al. Endoscopic ultrasound-guided transmural and percutaneous transhepatic gallbladder drainage are comparable for acute cholecystitis. Gastroenterology. 2012;142:805-11.

7. Itoi T, Kawakami H, Katanuma A, Irisawa A, Sofuni A, Itokawa F, et al. Endoscopic nasogallbladder tube or stent placement in acute cholecystitis: a preliminary prospective randomized trial in Japan (with videos). Gastrointest Endosc. 2015;81:111-8.

8. Kawano F, Yoshioka R, Gyoda Y, Ichida H, Mizuno T, Ishii S, et al. Laparoscopic cholecystectomy after endoscopic trans-papillary gallbladder stenting for acute cholecystitis: a pilot study of surgical feasibility. BMC Surg. 2021;21:1-7; doi:10.1186/s12893-021-01182-7.

9. Mu P, Lin Y, Zhang X, Lu Y, Yang M, Da Z, et al. The evaluation of ENGBD versus PTGBD in high-risk acute cholecystitis: a single-center prospective randomized controlled trial. EClinicalMedicine. 2020;31:100668; doi:10.1016/j.eclinm.2020.100668.

10. Inoue K, Ueno T, Nishina O, Douchi D, Shima K, Goto S, et al. Optimal timing of cholecystectomy after percutaneous gallbladder drainage for severe cholecystitis. BMC Gastroenterol. 2017;17:71.

11. Han IW, Jang JY, Kang MJ, Lee KB, Lee SE, Kim SW. Early versus delayed laparoscopic cholecystectomy after percutaneous transhepatic gallbladder drainage. J Hepatobiliary Pancreat Sci. 2012;19:187-93.

12. Choi JW, Park SH, Choi SY, Kim HS, Kim TH. Comparison of clinical result between early laparoscopic cholecystectomy and delayed laparoscopic cholecystectomy after percutaneous transhepatic gallbladder drainage for patients with complicated acute cholecystiti. Korean J Hepatobiliary Pancreat Surg. 2012;16:147-53.

13. Tan HY, Jiang DD, Li J, He K, Yang K. Percutaneous transhepatic gallbladder drainage combined with laparoscopic cholecystectomy: a meta-analysis of randomized controlled trials. J Laparoendosc Adv Surg Tech A. 2018;28:248-55. 
14. Itoi T, Coelho-Prabhu N, Baron TH. Endoscopic gallbladder drainage for management of acute cholecystitis. Gastrointest Endosc. 2010;71:1038-45.

15. Bakkaloglu H, Yanar H, Guloglu R, Taviloglu K, Tunca F, Aksoy M, et al. Ultrasound guided percutaneous cholecystostomy in high-risk patients for surgical intervension. World J Gastroenterol. 2006;12:7179-82.

16. Pannala R, Petersen BT, Gostout CJ, Topazian MD, Levy MJ, Baron TH. Endoscopic transpapillary gallbladder drainage: 10-year single center experience. Minerva Gastroenterol Dietol. 2008;54:107-13.

17. Sagami R, Hayasaka K, Nishikiori H, Harada H, Amano Y. Current status in the treatment of acute cholecystitis patients receiving antithrombotic therapy: is endoscopic drainage feasible? -a systematic review. Clin Endosc. 2020;53:176; doi:10.5946/ce.2019.177.

18. Widmer J, Alvarez P, Sharaiha RZ, Gossain S, Kedia P, Sarkaria S, et al. Endoscopic gallbladder drainage for acute cholecystitis, Clin Endosc. 2015;48:411; doi:10.5946/ce.2015.48.5.411.

19. Shin JU, Lee JK, Kim KH, Lee KH, Lee KT. Endoscopic naso-gallbladder drainage by using cholangioscopy for acute cholecystitis combined with cholangitis or choledocholithiasis (with video). Gastrointest Endosc. 2012;76:1052-5.

20. Oh D, Song TJ, Cho DH, Park DH, Seo DW, Lee SK, et al. EUS-guided cholecystostomy versus endoscopic transpapillary cholecystostomy for acute cholecystitis in high-risk surgical patients. Gastrointest Endosc. 2019;89:289-98.

21. lino C, Shimoyama T, Igarashi T, Aihara T, Ishii K, Sakamoto J, et al. Comparable efficacy of endoscopic transpapillary gallbladder drainage and percutaneous transhepatic gallbladder drainage in acute cholecystitis. Endosc Int Open. 2018;6:E594-601; doi:10.1055/s-0044-102091.

22. Khan MA, Atiq O, Kubiliun N, Ali B, Kamal F, Nollan R, et al. Efficacy and safety of endoscopic gallbladder drainage in acute cholecystitis: is it better than percutaneous gallbladder drainage? Gastrointest Endosc. 2017;85:76-87.

23. Itoi T. New era in acute cholecystitis treatment: encouraging results for interventional endoscopists. Gastrointest Endosc. 2017;85:8.

\section{Tables}

Table 1 Characteristics of EGBD and PTGBD patients before gallbladder drainage 


\begin{tabular}{llll}
\hline Characteristics & EGBD $(n=7)$ & PTGBD $(n=26)$ & $p$ value \\
\hline Age & $70(63-85)$ & $71(56-88)$ & 0.7 \\
Sex (male/female) & $4 / 3$ & $14 / 12$ & 1.0 \\
$\begin{array}{l}\text { Anticoagulant } \\
\text { therapy }\end{array}$ & & \\
Yes & 2 & 8 & 1.0 \\
No & 5 & 18 & \\
Time to opelation & $96(26-124)$ & $66(32-122)$ & 0.03 \\
(day) & & & \\
Grade* & & $9(35 \%)$ & 0.71 \\
I & $3(43 \%)$ & $12(46 \%)$ & \\
II & $4(57 \%)$ & $5(19 \%)$ & \\
III & $0(0 \%)$ & & \\
\hline
\end{tabular}

*Classified by the Tokyo guidelines

Data are presented as median (range) or number

Table 2 Surgical results in patients with and without drainage

\begin{tabular}{llll}
\hline & No drainage $(\mathrm{n}=68)$ & Drainage $(\mathrm{n}=33)$ & $P$ value \\
\hline Surgery time (min) & $107(51-304)$ & $148(75-299)$ & 0.0028 \\
Blood loss (ml) & $5(0-201)$ & $7(1-202)$ & 0.0085 \\
Conversion to open surgery & 0 & 0 & \\
Cystic duct closure & & & \\
5mm clip & 48 & 9 & 0.00018 \\
12mm clip & 5 & 3 & \\
automatic suturing device & 11 & 16 & \\
subtotal cholecystectomy & 4 & 5 & \\
Postoperative complication & & & \\
Clavian-Dindo criteria & & 33 & 0.59 \\
no complication & 64 & 0 & \\
Grade II & 2 & 0 & \\
Grade III & 2 & $7(2-17)$ & \\
Postoperative stay(day) & $4(1-17)$ & & \\
\hline
\end{tabular}

Data are presented as median (range) or number 
Table 3 Surgical results in EGBD and PTGBD patients

\begin{tabular}{llll}
\hline Characteristics & EGBD $(n=7)$ & PTGBD $(n=26)$ & $p$ value \\
\hline Age & $70(63-85)$ & $71(56-88)$ & 0.7 \\
Sex (male/female) & $4 / 3$ & $14 / 12$ & 1.0 \\
$\begin{array}{l}\text { Anticoagulant } \\
\text { therapy }\end{array}$ & & \\
Yes & 2 & 8 & 1.0 \\
No & 5 & 18 & \\
Time to opelation & $96(26-124)$ & $66(32-122)$ & 0.03 \\
(day) & & & \\
Grade* & & $9(35 \%)$ & 0.71 \\
I & $3(43 \%)$ & $12(46 \%)$ & \\
II & $4(57 \%)$ & $5(19 \%)$ & \\
III & $0(0 \%)$ & & \\
\hline
\end{tabular}

*Classified by the Tokyo guidelines

Data are presented as median (range) or number

\section{Figures}


Fig.1 Flow of 101 patients who underwent cholecystectomy for cholecystitis

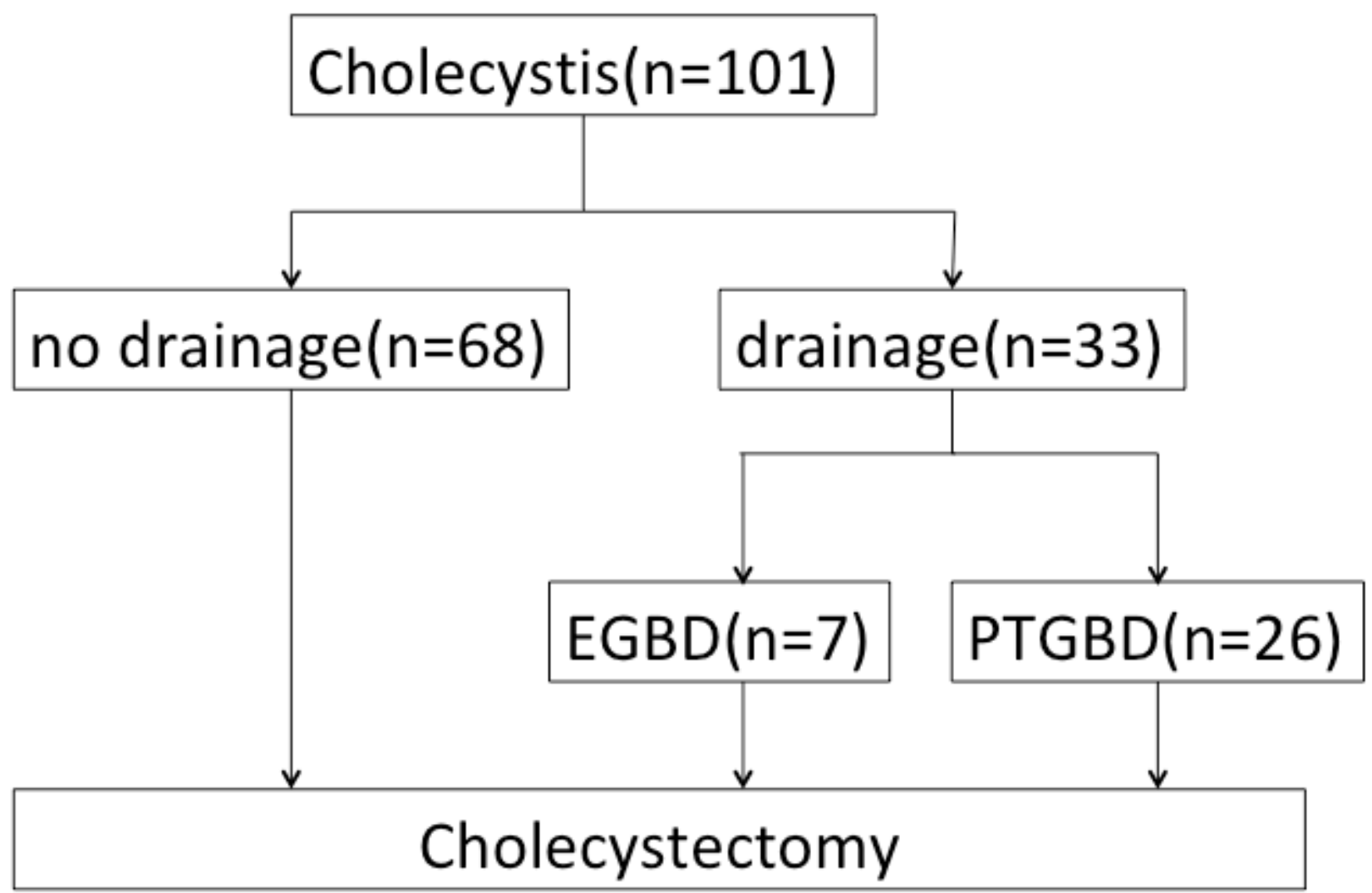

Figure 1

See image above for figure legend.

Figure 2

See image above for figure legend. 